\title{
Contextual effects on individual voting behaviour: the impact of party system nationalization in Europe
}

\author{
NICOLA MAGGINI ${ }^{1 *}$ AND VINCENZO EMANUELE ${ }^{2}$ \\ ${ }^{1}$ University of Florence, Department of Political and Social Sciences, Florence, Italy \\ ${ }^{2}$ LUISS Guido Carli, Department of Political Sciences, Rome, Italy
}

This article has the purpose to assess if and how party system nationalization affects individual voting behaviour. Previous studies on party system nationalization have focused on systemic processes, exclusively dealing with aggregate data. The authors address this topic from a new empirical perspective, arguing that party system nationalization could act as a context dimension interacting with the vote choice function. How does this specific context dimension moderate the explanatory power of individual-level characteristics? On which determinants of vote choice does party system nationalization have a greater impact? To answer these questions, the authors focus on 23 European countries through the use of the 2009 European Election Study. The empirical analysis shows that in nationalized contexts the impact of the left-right dimension on party support is higher than in territorialized contexts, whereas that of class as well as of culture-related variables is lower. The authors also discuss the implications of these findings.

Keywords: party system nationalization; voting behaviour; contextual effects; EU countries; multi-level analysis

\section{Introduction}

The purpose of this article is to assess if and how party system nationalization conceived as a contextual dimension - affects individual voting behaviour. Contemporary political science shows clearly that 'context matters' (Lane and Ersson, 1990; Marsh, 2002). As far as voting behaviour is concerned, contextual effects are undoubtedly among the key factors influencing voting decision. Comparative studies on electoral behaviour are increasingly influenced by the expectation that characteristics of context, in which party choice takes place, are an important source of its variation. ${ }^{1}$ In the current analysis, we focus on the territorial

\footnotetext{
${ }^{1}$ On this point scholars have considered different contextual dimensions as factors influencing voting behaviour: amongst the many, the level of polarization between parties has been taken into account by Thomassen (2005); the role of political institutions has been considered by Klingemann (2009) and Dalton and Anderson (2011); and the effects of the interpersonal network of discussion has been investigated by Huckfeldt and Sprague (1993).
}

*E-mail: nicolamaggini@libero.it, vincenzoemanuele@hotmail.it 
dimension of context ${ }^{2}$ and we conceive party system nationalization as the level of territorial homogeneity of party support in a given country. It is therefore considered as a contextual variable that may moderate the impact of individuallevel characteristics on voting behaviour. In this regard, whether or not political parties are able to represent nationwide interests and preferences of the voters has important consequences on the way people vote.

Previous research on party system nationalization has studied it as a dependent variable looking for its empirical determinants, ${ }^{3}$ generally through a systemic point of view and the use of aggregate data. The novelty of this analysis is that we address this topic from a new empirical perspective, arguing that party system nationalization could act as a context dimension interacting with the vote choice function, thus combining a systemic-level variable with individual-level data.

Our empirical analysis focuses on 23 European countries through the use of the 2009 European Election Study adding to the original data set the party system nationalization index for each country.

The structure of the article is as follows: first section briefly reviews the literature on party system nationalization and introduces the hypotheses to be tested; second section shows the different levels of party system nationalization occurring in 23 European countries; third section presents the empirical model: the multi-level analysis design, the dependent variable [the propensity to vote (Ptv) for a party in general], and the explanatory factors (both the individual-level variables and the party-level ones), which will be interacted with nationalization; finally fourth section shows the findings of the empirical test and verifies if the hypotheses are confirmed or disproved; a concluding section follows.

\section{Theory, measures, and hypotheses}

The theory of nationalization of politics has been initially developed in the American setting (Schattschneider, 1960; Stokes, 1965, 1967). In the specific European context, the most systematic contribution, from both a theoretical and empirical point of view, has been provided by Caramani (2004). According to Caramani, the nationalization of politics is a major long-term political phenomenon that deals with the historical evolution from highly localized and territorialized politics - which characterized the early phases of electoral competition - towards the formation of national electorates and party systems and is carried out through the progressive reduction of the territoriality of political cleavages. The starting point of Caramani's analysis is represented by Rokkan's macro-sociological study

\footnotetext{
2 The importance of territory on voting behaviour has been widely discussed by political science (Lipset and Rokkan, 1967; Rose and Urwin, 1975) and political geography (Siegfried, 1913; Agnew, 1987).

${ }^{3}$ Recently published articles have focused on party system nationalization conceived as an independent variable being able to affect the composition of central government expenditures (Castañeda-Angarita, 2013) and the provisions of the public health care service (Hicken et al., 2008).
} 
on the territorial structuring of the European party systems (1970), as well as by previous empirical analyses about regional differentiation in Western nations (Rose and Urwin, 1975; Ersson et al., 1985) and by the substantial set of studies on the nation-building process and the consequent centre-periphery conflict in Europe (Tilly, 1975; Torsvik, 1981; Rokkan and Urwin, 1982).

Caramani clearly sets both the timing and the main determinants of the nationalization process. As far as the timing of the process is taken into account, Caramani states that the formation of national electorates and party systems and the progressive homogenization of party support in Europe took place in the early phases of the development of electoral competition, between the end of the 19th century and World War I.

Moving to the factors affecting the nationalization process in Europe, Caramani's theoretical scheme $(2004,195)$ is based on the three fundamental dimensions concerning the structuring of the political space: state formation, democratization, and nation-building.

To begin with, the process of state formation has historically concerned the definition and the closing of external state boundaries and the related definition of the citizenship. Using Hirschman's terminology (1970), this strengthening of external boundaries resulted in a reduction of the exit options.

Second, the process of democratization concerns the development of mass politics and party competition through the diffusion of the institutional channels of representation and the progressive extension and equalization of voting rights to previously excluded citizens. Quoting Hirschman (1970) again, democratization favoured the development of territorial voice channels.

Finally, the nation-building process refers to the centralizing effort, led by the nation-building elites, in order to penetrate the country's peripheries and achieve their political mobilization, economic integration, and cultural standardization. By doing so, political cleavages, which shape the expression of voice in the political system and structure the constellations of party alliances and oppositions, lost part of their former territoriality. ${ }^{4}$ As the nation-building process was successfully carried out, the old territorial lines of conflict (originated by ethnic, linguistic, or religious divisions), characterizing the early phases of electoral competition, were replaced by functional cleavages cutting across territorial units. These three macroprocesses (state formation, democratization, and nation-building) and their political consequences (reduction of exit options, development of internal voice channels, and progressive reduction of their territoriality) structured the European political space and fostered the evolution of European countries towards the emergence of a nationalized pattern of electoral competition. Nonetheless, these

\footnotetext{
4 The territoriality of the political cleavages and of the party families stemming from each of them varies from country to country and over time. In general, Lipset and Rokkan (1967: 1-64) distinguish between functional cleavages (state church and class) and territorial ones (centre-periphery and rural-urban), although in some way all four hold a certain degree of territoriality.
} 
processes have not always been entirely successful; in some polities the nationalization process has not been fully achieved, whereas in some others it has completely failed, thus leading to the exit option or to the territorial expression of voice.

Given this historical process, it is important to assess how, nowadays, party system nationalization (from now on PSN), may have implications on the vote choice function. As stated in the Introduction section, we consider PSN as a contextual variable that may moderate the impact of individual-level characteristics on voting behaviour. In this regard, whether or not political parties rely on nationalized patterns of territorial configurations has important consequences on the way people vote. The process of PSN has led to the emergence of nationwide electoral alignments and the rise of territorially homogenous patterns of electoral behaviour. On the contrary, where nationalization has historically failed, the voter is 'faced with a different practical choice, with different names and possibly different parties on the ballot paper according to the constituency [...] this difference affects all in an area, and this type of contextual effect for this reason has been called a global effect' (Marsh, 2002: 207).

On the basis of these considerations, we hypothesize that PSN may moderate the impact of some individual-level characteristics on the vote choice function. We will test three specific conditional hypotheses in detail. A conditional hypothesis is simply one in which a relationship between two or more variables depends on the value of one or more other variables.

The first hypothesis concerns the relationship between the presence of a pattern of party competition based on the left-right dimension and voting behaviour. As aforementioned, the formation of national party systems in Europe has taken place in the early phases of electoral competition, before the introduction of the universal suffrage. It has consisted of a process of progressive de-territorialization of political cleavages, which has brought to the predominance of a nationwide pattern of party competition structured along a functional left-right axis. As stressed by Caramani (2004: 199-204), this process was carried out during the 19th century through the emergence of Liberal and Conservative parties, which represented the left and the right side of the political space, respectively. The opposition between Liberals and Conservatives had not a territorial nature but a functional one, as it was based on specific interests and values. The functional division between left and right has become in the following decades (and up to now) the overwhelming dimension of party competition in the European context. It has been reinforced by the inclusion of mass working electorates through franchise extension and the emergence of Social-Democratic parties triggered by the Industrial Revolution. It follows that we expect a higher impact of the left-right dimension on voting behaviour in highly nationalized contexts, and vice versa. Our first conditional hypothesis is therefore as follows:

HYPOTHESIS 1: The impact of the left-right dimension on vote choice is expected to be larger in contexts characterized by higher PSN. 
The second hypothesis to be tested is partially linked to the first one and focuses on the impact of class cleavage on voting behaviour. The class cleavage stemmed from the Industrial Revolution at the end of the 19th century and consists of the functional opposition between the interest of the rising class of industrial workers and that of the employers. This cleavage found its political expression through the advent of Social-Democratic parties, which, in a few years became crucial actors in the European party systems. These parties rapidly spread their support within their countries, thus strongly contributing to the territorial homogenization of party support and becoming one of the most nationalized party families in Europe. ${ }^{5}$ As stated by Caramani (2004: 196), the class cleavage is therefore a 'homogenizing cleavage' because it further contributed to structure party competition alongside functional left-right dimension, and we expect that its impact on voting behaviour should increase when PSN is higher. Our second conditional hypothesis is therefore as follows:

HYPOTHESIS 2: The impact of class cleavage on vote choice is expected to be larger in contexts characterized by higher PSN.

Although the class cleavage has a homogenizing impact on the territorial configuration of party support, other cleavages, namely the cultural ones, exert the opposite effect. Many scholars, from the classical study by Lipset and Rokkan (1967) up to most recent articles (Sikk and Bochsler, 2008: 3; Lago and Lago, 2010: 6-7) have shown that the presence of ethnic, linguistic, or religious within-country differences is a major source of territorial heterogeneity in Europe. As stressed by Caramani 'the survival of territoriality in politics today can be principally explained through cultural cleavages that resisted the homogenizing impact of class politics' (2005: 318). In particular, as we will emphasize in the next section, the rise of the centre-periphery cleavage as well as of the religious one fosters the birth and the electoral growth of parties for territorial defence whose support is territorially concentrated. For this reason, our third conditional hypothesis is as follows:

HYPOTHESIS 3: The impact of culture-related variables on vote choice is expected to be larger in contexts characterized by lower PSN.

\section{Levels of nationalization across Europe}

Before moving to the empirical analysis, it is important to show the ways in which PSN is measured. The literature has proposed many different indicators, ${ }^{6}$ according to the specific meaning scholars assign to the concept of nationalization. Morgenstern et al. (2009) distinguish between a dynamic dimension of

\footnotetext{
${ }^{5}$ See the empirical results on this point by Ersson et al. (1985: 183).

${ }^{6}$ For a detailed and comprehensive review on the various indices and their respective shortcomings, see Caramani (2004: 61-70) and Bochsler (2010a: 157).
} 
nationalization, focusing on the comparison between two subsequent elections, and a static or distributional dimension of nationalization, which study it in a given election. From this general distinction, different empirical measures follow. Among the so-called 'distribution coefficients', namely those indices that measure nationalization at a given election and are therefore suitable for this research, one of the most accurate is the Party Nationalization Score (PNS), developed by Jones and Mainwaring (2003: 142) that conceives vote nationalization as the level of homogeneity of party support across the territorial units of a country. It is nothing but the inverted Gini coefficient, a widely used index of inequality across units. The PNS varies from 0 (the party receives $100 \%$ of its votes in one subnational unit and $0 \%$ in all the rest) to 1 (it receives the same share of votes in every subnational unit). In order to take into account the systemic level of nationalization, they develop the Party System Nationalization Score (PSNS) that consists of the sum of the PNS of each party, weighted for its national share of votes. The contribution of every party to the PSNS is thus proportionate to its electoral strength.

Although it is surely superior to its existing alternatives and allows for both cross-country and cross-time comparability, PNS still retains two main shortcomings, as underlined by Bochsler (2010a: 157): it does not take into account either the size of territorial units (measured in terms of voters) or the different number of units (all else being equal, if the number of units increases, the score of the PNS decreases). In order to correct these two failings, Bochsler (2010a: 164) developed the standardized Party Nationalization Score (sPNS). Its complex formula ${ }^{7}$ is exponentiated to $1 / \log (E)$ where $\log$ stands for the logarithmic function and $E$ represents the effective number of territorial units ${ }^{8}$ and allows for taking into account the size and the number of the territorial units, thus solving both the failings of the simple PNS.

Performing as one of the most reliable measures of 'static' PSN' (Bochsler, 2010a: 164-165; Andreadis, 2011), the sPSNS (i.e. the systemic formula of the index) has been chosen as the reference index to operationalize the intervening variable (PSN) of the current analysis.

Table 1 reports the countries included in the analysis, the election year on which we have calculated Bochsler's standardized index, the number of territorial units in which electoral data have been disaggregated, and finally the sPSNS index for each

\footnotetext{
7 Assuming that the heterogeneity measured at a lower territorial level, that is $\operatorname{PNS}\left(n^{2}\right)$, corresponds to the squared heterogeneity measured at a higher level, that is $\operatorname{PNS}(n)$ - where $n$ is the number of units, we have $\operatorname{PNS}\left(n^{2}\right)=\operatorname{PNS}(n)^{2}$. After introducing the logarithmic function, the final result is the following formula: sPNS $=\left(1-G_{E}\right)^{(\log 10 / \log E)}=\left(1-G_{E}\right)^{(1 / \log E)}=P N S_{E}^{(1 / \log E)}$. In the formula, $G$ stands for Gini, $E$ stands for the effective number of territorial units, and log stands for the logarithmic function.

${ }^{8}$ Similar to the effective number of parties of Laakso and Taagepera (1979).

${ }^{9}$ However, a recently published article (Morgenstern et al., 2014) underlines that the Bochsler index has one important problem related to the weighting mechanism concerning the number and size of districts. This may produce misleading results under particular circumstances. Their conclusion is that, despite the advances provided by sPSNS, a perfect measure of 'static' party system nationalization does not exist, and each index has its own trade-off.
} 
Table 1. Levels of party system nationalization across Europe

\begin{tabular}{lccc}
\hline \hline Countries & Election years & Number of territorial units & sPSNS \\
\hline Austria & 2008 & 9 & 0.835 \\
Belgium & 2010 & 11 & 0.484 \\
Bulgaria & 2009 & 29 & 0.824 \\
Czech Republic & 2006 & 14 & 0.901 \\
Denmark & 2011 & 10 & 0.876 \\
Estonia & 2007 & 12 & 0.834 \\
Finland & 2011 & 15 & 0.794 \\
France & 2012 & 22 & 0.862 \\
Germany & 2009 & 16 & 0.777 \\
Greece & 2009 & 56 & 0.921 \\
Hungary & 2006 & 20 & 0.915 \\
Ireland & 2011 & 43 & 0.834 \\
Italy & 2008 & 20 & 0.837 \\
Latvia & 2006 & 34 & 0.741 \\
The Netherlands & 2010 & 12 & 0.872 \\
Poland & 2001 & 41 & 0.873 \\
Portugal & 2009 & 20 & 0.887 \\
Romania & 2000 & 42 & 0.804 \\
Slovakia & 2002 & 79 & 0.806 \\
Slovenia & 2004 & 82 & 0.891 \\
Spain & 2011 & 12 & 0.803 \\
Sweden & 2010 & & 0.897 \\
United Kingdom & 2010 & 29 & 0.798 \\
\hline \hline
\end{tabular}

sPSNS = standardized Party System Nationalization Score.

All the elections considered are parliamentary elections for the Lower House.

Source: sPSNS values for Czech Republic, Estonia, Hungary, Latvia, Poland, Slovakia, and Slovenia have been taken from Bochsler (2010a). The sPSNS value for Romania has been taken from CLEA (Constituency-Level Election Archive) of Kollman, Hicken, Caramani, and Baken. Values for all the remaining countries are the results of our calculations on Official Data.

country. As aforementioned, we have used the EES survey of the year 2009. Therefore, in order to act as a reliable intervening variable, the levels of PSN for the European countries should refer to a very recent year (as close as possible to 2009), in most cases corresponding to the last general election. This general goal has been compiled for all except four cases (Romania, Poland, Slovakia, and Slovenia) for which we have data only in the early 2000s. Conversely, Cyprus, Malta, Lithuania, and Luxembourg have been excluded because territorially disaggregated data were not available. Therefore, 23 of 27 European Union (EU) members have been selected.

The number of territorial units shows quite a high variability, because it ranges from the eight units of Slovenia to the 79 of Slovakia. However, these differences do not represent a problem, as Bochsler's index takes the number of territorial units 
into account, thus allowing for a reliable cross-country comparability. The sPSNS coefficients go from the extremely low value of Belgium (0.484) to the highly nationalized case of Greece (0.921).

Western European countries are long-term consolidated democracies that experienced the historical processes of mass democratization and electoral mobilization about one century ago (with the significant exceptions of Spain, Portugal, and Greece). Here, the party systems became nationalized at the beginning of the 20th century, with the structuring of the political space around national alignments of partisan alternatives, according with the specific system of cleavages arisen in each country. During the 1920 s, these party systems - by that time almost nationalized - became 'frozen' and kept their stable alignments intact until the 1960s, as underlined by the famous freezing hypothesis, formulated for the first time by Lipset and Rokkan (1967: 50). Since the 1970s, Western democracies have undergone a process of growing instability, with an increase in the number of parties and in the levels of electoral volatility (Dalton et al., 1984) and, in some cases, a reversal of the historical trend of nationalization emphasized by Caramani (2004), towards a de-nationalization of their territorial configurations.

The values of sPSNS for the 14 Western EU countries of our sample are reported in Figure 1. What emerges in a striking way in the chart is that Belgium represents a real outlier in comparison with all the other countries; both the Western and Eastern ones. With its score of 0.484 , Belgium is located about 0.300 far from the secondmost territorially heterogeneous country in Western Europe; that is, Germany. The extremely low value of the Belgian case is understandable if we consider its recent electoral history. The country has always been culturally fragmented along the territorial division between the Catholic and the Dutch-speaking Flanders region in the North, and the secularized and French-speaking Walloon region in the South. During the 1970s, it experienced the complete split of its previously unified party

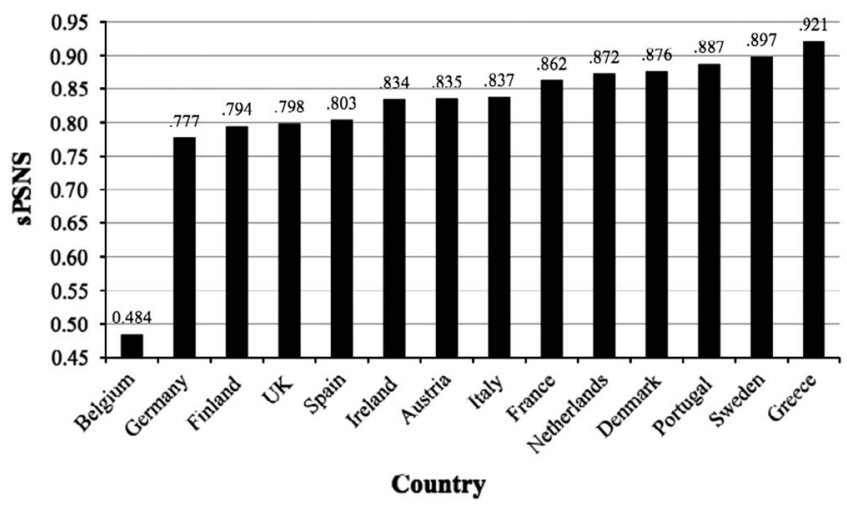

Figure 1 Party system nationalization of Western EU countries. EU = European Union; sPSNS $=$ standardized Party System Nationalization Score. 
system into two systems; the Flemish and the Walloon systems, with the division of the three main parties, the Christian-Democratic and the Liberal and Socialist parties along the linguistic cleavage, in addition to the emergence of many ethno-regionalists parties, such as the Flemish Volksunie and Vlaams Belang, and the Walloon Rassemblement Walloon (De Winter and Dumont, 1999).

The overall mean of the Western European group of countries is 0.820 and the median is 0.836 , even if, with the exclusion of the extreme Belgian case, the remainder countries are clustered in less than 0.150 points of Bochsler's index; however, some important differences emerge. Three subsets can be distinguished: the regionalized territorial configurations (Germany, Finland, United Kingdom, and Spain), the highly nationalized ones (Greece, Sweden, Portugal, Denmark, the Netherlands, and, to a lesser extent, France), and the subset of party systems that can be qualified as nationalized, but with important regional differences (Ireland, Austria, and Italy).

The first subset consists of those countries whose level of sPSNS falls below the overall mean. The relatively low level of PSN of this group of countries is caused mainly by two factors: the presence of some important ethnic minorities or regionalist parties, and the within-country differences in the territorial configuration of support for the main national parties. As far as the former factor is concerned, in Germany the nationalization index is kept at a relatively low level for the presence of the biggest European regionalist party, the Bavarian CSU (Christlich Soziale Union), whereas in Spain the almost two-party system format is still surrounded by a myriad of small regionalist parties claiming more autonomy from the central power. In Finland, the ethnic party, the Swedish people's party (Ruotsalainen kansanpuolue), represents the substantive Swedish-speaking minority, which is concentrated in the southwest (Vaasa, Helsinki, and Uusimaa) and in the small island of Aland. Finally, in the United Kingdom, the centreperiphery cleavage has been successfully politicized by two regionalist parties; the Scottish National Party in Scotland and the Playd Cymru in Wales. However, the rather low level of vote nationalization in the country is mainly because of the second factor mentioned above, namely the regional distinctiveness of its three main national parties; the Conservative dominates the south and the east of England, the Labour party is particularly strong in the peripheral regions of Scotland and Wales and in the industrial north of England, whereas the Liberals are concentrated in their bastions of southwest England. On the opposite side of Figure 1, we find those countries showing high PSN. Most of them are characterized by a high level of ethnic, linguistic, and religious homogeneity. In some of them (Greece, Portugal, and, to a lesser extent, France), relevant territorial fractures lack; in other countries they are losing importance, as the urban-rural cleavage in Scandinavian countries, or the religious cleavage in the Dutch case.

The third subset of countries in Figure 1 consists of three systems whose nationalization index falls around the median value: Ireland, Austria, and Italy. Ireland has an idiosyncratic party system, where the main line of conflict concerns 
the positions of the two main parties, Fianna Fáil and Fine Gael, about the 1921 Anglo-Irish Treaty that established the Irish Free State. Here, some important regional differences within party support emerge (Gallagher, 1998). Both Austria and Italy are instead characterized by the presence of strong and time-resistant political subcultures ${ }^{10}$ that contributed to retaining the uneven electoral geography of these countries. Austria has maintained so far its division between a 'red zone' of socialist prevalence, the urbanized and secularized region of Vienna, and a 'black zone', the rural and Catholic regions of Tyrol, Voralberg, and Lower Austria, where the Christian-Democratic ÖVP (Österreichische Volkspartei) is still predominant. Regarding Italy, despite the profound changes experienced during the last 20 years, with the shift from the extreme polarized pluralism (Sartori, 1976) of the First Republic (1948-92) to the fragmented bipolarism (Chiaramonte, 2007: 404) of the so-called Second Republic (1994-present), the Italian party system has preserved the stability and the continuity of its regional differences very well. As in the Austrian case, a 'red belt' of left predominance is clearly distinguishable, as well as the centre-right prevalence in the northeast of the country, a former Christian-Democratic stronghold (formerly known as the 'white zone').

Central and Eastern European countries show similar contextual factors, such as the legacy of their communist past, their recent political transition to the democratic rule and, in many cases, a persistent lack of institutionalization. These countries are often characterized by very unstable party systems that usually experience big electoral changes in terms of inter-election volatility as well as the entry of new challengers into the electoral arena (Sikk, 2005; Tavits, 2005). ${ }^{11}$ As a consequence, the levels of PSN in the Eastern countries must be interpreted carefully, being conscious that the results may vary consistently over time.

However, as underlined by Bochsler $(2010 \mathrm{~b})$, the factors that are able to better explain the different territorial configurations of these countries are the role of social divides and political cleavages and the impact of national electoral thresholds, whereas the institutional explanation, looking at the role of the centralization of governments (Chhibber and Kollman, 2004), does not hold. As far as the former factor is concerned, the overwhelming view is that cleavages, especially if they are narrowly defined, are of limited relevance in the region (Elster et al., 1998: 247-270). However, quoting Bochsler, 'One social divide ${ }^{12}$ appears to be an exception to the rule: the ethnic divide is salient in Central and Eastern Europe (Evans and Need, 2002) and helps many parties to mobilize their voters (Elster et al., 1998, 252). Ethnic minorities exist in almost all countries, and they

\footnotetext{
${ }^{10}$ In the Austrian case the appropriate term is Lager.

11 The case of Poland deserves to be mentioned; the mean level of total volatility between 1991 and 2005 reaches the sensational value of $40.6 \%$. Moreover, in 1993 and 2005 there is a complete renewal of the electoral supply on the centre-right bloc (Grilli di Cortona, 2007: 222).

12 Bochsler employs the term 'social divide' rather than cleavage, acknowledging that these divides have different characteristics from the cleavages described by Lipset and Rokkan (1967).
} 


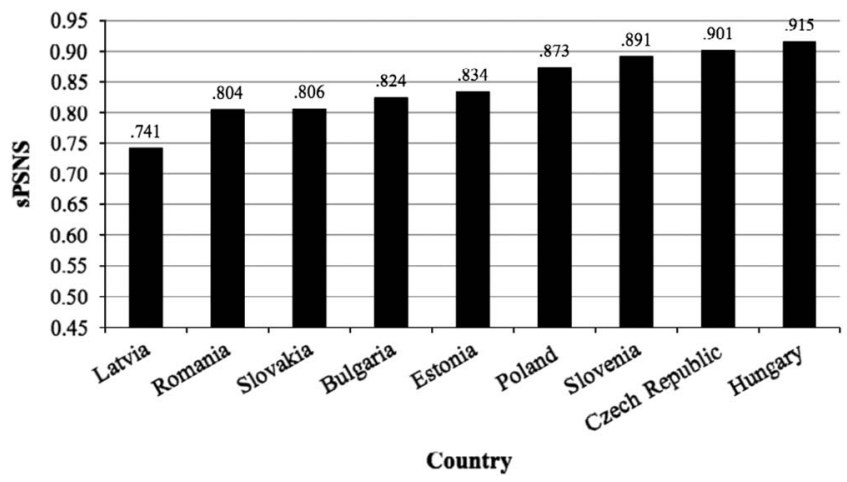

Figure 2 Party system nationalization of Central and Eastern European Union countries. EU = European Union; sPSNS = standardized Party System Nationalization Score.

vote in large numbers for their own parties' (2010b: 9-10). Furthermore, the presence of a national legal threshold might exert constraints against the formation of regional parties (Cox, 1999: 159). Many Central and Eastern European regional parties are competitive only in one region of the country, and a substantive national threshold left them little chance to get access to Parliament. That is why in some of these countries party nationalization is kept at high levels, even if minorities and territorial ethnic divides persist.

Figure 2 shows the values of sPSNS for Central and Eastern EU countries. There is a wide variability, ranging from 0.741 of Latvia to 0.915 of Hungary. This means that, looking for a clear-cut generalization, this sample holds two subsets that are clearly distinguishable; the regionalized countries (Latvia, Romania, Slovakia, and Bulgaria) with a sPSNS that is lower than the overall mean $(0.843)$, and the nationalized polities (Hungary, Czech Republic, Slovenia, and Poland), whose sPSNS fall over the mean, whereas Estonia (0.834) retains an intermediate position.

According to Bochsler (2010b), in Slovakia, the Balkan democracies of Bulgaria and Romania, as well as in the Baltic states of Latvia and Estonia, the electoral geography is closely linked to the ethnic structure of the territory. It is not by chance that they appear as the most territorially heterogeneous party systems. In the nationalized polities of Hungary, Czech Republic, Slovenia, and Poland the high levels of nationalization are mainly because of the effect of the electoral system and in particular to the homogenizing role of the national threshold $(4 \%$ or higher in each of these countries).

\section{Data and methods}

The goal of the analysis is to find out the factors on which PSN has a greater impact in order to explain the voting decision. Thus, it is a synchronic comparison, and 
being a large- $N$ study, the analysis relies on quantitative methods. In order to test our hypotheses, we built a multi-level mixed-effects regression model ${ }^{13}$ with a stacked data matrix. ${ }^{14}$ Our research strategy leads us to consider the largest number of parties and of countries in order to achieve the maximum degree of generality. In this way, our findings may travel across countries, minimizing the impact of contingent and idiosyncratic national factors.

For the above-mentioned reasons, we employed data from the PIREDEU study. In particular, we employed the voter-level survey data from the 2009 European Election Study (van Egmond et al., 2011). It is a representative mass survey data including 27 virtually identical national samples. These surveys are related to the European Parliament elections. They are second-order elections (Reif and Schmitt, 1980 ) in which party competition is carried out on a national basis. Moreover, parties seeking votes in these elections are national parties. It means that specific European factors are, at best, of marginal importance. Therefore, we have at the same time inter-country variance and cross-national context uniformity: this allows us to consider European elections as a 'laboratory' for national political processes (van der Eijk and Franklin, 1996; van der Brug et al., 2008). In our analysis, we have added to the original data set the standardized Bochsler's score (sPSNS) for 23 of 27 countries, as previously mentioned.

The analysis is divided into two stages: first, the relevant independent and dependent variables have been selected; then, a stacked data matrix and a multilevel mixed-effects regression model have been built. We have employed as a dependent variable the Ptv for a party in general, following a proved measurement and an analysis strategy developed by some scholars (van der Eijk and Franklin, 1996; van der Eijk et al., 2006). The Ptv has been measured by asking respondents to report separately for each party the likelihood that they will ever vote for that party. ${ }^{15}$ The independent variables are divided into two main categories: the individual characteristics and the party features. As far as the individual characteristics are concerned, the main independent variables of the current research according to our conditional hypotheses are class-cleavage-related variables (i.e. working class ${ }^{16}$ and union membership ${ }^{17}$ ) and culture-related variables (i.e. minority ${ }^{18}$ and religiosity ${ }^{19}$ ). The importance of sociological variables regarding voting behaviour has been stressed in the field of electoral studies by the so-called Michigan School

13 The multi-level regression that we applied in Stata 12 is xtmixed.

14 In Stata 12 we used the Ptvtools package.

15 The Ptv is measured on an 11-point scale from 0 to 10 , where 0 means 'certainly I would never vote for this party' and 10 means 'certainly I would vote for this party at some time'.

16 This variable is a dummy based on the respondent's perception to belong to the working class.

17 This variable is a dummy based on the reported belonging of respondent to trade unions.

18 This variable is a dummy based on the respondent's perception to belong to minorities different from the national group.

19 This variable measures how religious the respondent is on a scale from 0 to 10 , where 0 stands for 'not at all religious' and 10 for 'very religious'. 
(Campbell et al., 1960), by the so-called Columbia School (Lazarsfeld et al., 1944; Berelson et al., 1954), and by the cleavage theory (Lipset and Rokkan, 1967). All these theories belong to the so-called socio-psychological model, according to which voters are guided and encapsulated (Bartolini and Mair, 1990; Bartolini, 2000) by their own social characteristics, by their social allegiances, and by their psychological identification with a specific party (Campbell et al., 1960). Furthermore, according to the 'funnel of causality' approach (Campbell et al., 1960), the voting process can be described in terms of a funnel; in the mouth of the funnel, there are the socio-economic conditions that generate society's main political divisions. These factors influence the structure of the party systems, but they are far from the voting decisions of citizens. Moving along the funnel (at the bottom of which there is the voting decision), one can see how socio-economic conditions influence the primary groups and values that are more explicitly tied to political attitudes. After selecting the socio-demographic variables, ${ }^{20}$ it is necessary to characterize the other independent control variables: political awareness, ${ }^{21}$ and opinions on a specific issue related to the $\mathrm{EU}^{22}{ }^{22}$ which are all variables that are closer to voting decisions according to the above-cited 'funnel of causality' approach. The importance of issues is stressed by theories of issue voting: voters compare their own position with that of parties defined in terms of specific issues. Voters use such issues as criteria for choice (Converse, 1975; Smith, 1989; Kuechler, 1991). Finally, the last independent variable that has to be included in the model is that of self-placement along the left/right spectrum. ${ }^{23}$ Indeed, rational choice theories propose the idea that voters choose among candidates and parties on the basis of alternative packages of policy outcomes. Alternative sets of policy proposals are often encapsulated in more general ideological dimensions; the most important being the left/right distinction (Downs, 1957). The assumption is that voters are able to characterize not only parties in such terms, but themselves as well. The party choice can be viewed in terms of a comparison between one's own position and that of parties $^{24}$ in terms of ideology.

The strategy of analysis is based on a novel application to vote choice variables of the stacked data set, multi-level analysis design originally developed by van der Eijk and Franklin $(1996,2009)$ whose advantages are the inclusion of all (including

\footnotetext{
${ }^{20}$ We have considered as control variables other socio-demographic characteristics (i.e. gender, age, education, family income, church attendance, marital status, and employment status) according to the main studies on voting behaviour (among them, see van der Eijk and Franklin, 1996; De Sio and Franklin, 2012).

21 Level of political interest of respondent measured on a four-point scale.

${ }^{22}$ In particular, opinion about the belonging of the respondent's country to the EU. The position of the voter on this issue is determined on a three-point scale with scores corresponding to agreement, disagreement, and a neutral position.

${ }^{23}$ The political self-placement of the respondent is measured on a scale from 0 to 10 , where 0 means 'left' and 10 means 'right'.

24 The ideological position of each party is determined by asking respondents to place parties on the same scale from 0 to 10 , where 0 means 'left' and 10 means 'right'.
} 
small) parties, as well as the possibilities of including party features in the explanatory model. As stated previously, the dependent variable is the Ptv for a party in general. Party choice would normally be represented in a data matrix as different variables for each party, which would not lend themselves to being analysed simultaneously. At any rate, we are looking for determinants of voting in general rather than a specific model for one party or another. We need a research design in which inter-party (individual level) and intra-party variances are simultaneously taken into account. Stacked analysis makes it possible. Consequently, we have to reshape the original data into a so-called stacked form in which the Ptvs reported for each party by each respondent are converted into different values of the same generic Ptv variable for duplicate observations of the same respondent across different parties. In this way, each respondent is represented by a number of rows in the stacked data set, as many as the number of parties for which he or she gives a probability for which to vote (van der Eijk et al., 2006). Therefore, after stacking, the unit of analysis are not respondents, but responses (individual $\times$ parties). In this stacked data set, there are two kinds of independent variables: party-specific variables and party-unspecific variables. The first ones are party features such as party size (measured as the seats share of a given party), party positions on the left-right scale, and party closeness (whether a party was one that a respondent felt close to). ${ }^{25}$ The second ones are individual-level variables that in the stacked data set have the same value across all the within-respondent observations, as they are not directly related to party preferences in the voter's mind (e.g. gender, education, etc.). Therefore, we need to capture the empirical relationship between voters and parties. In order to do that, we transformed spatial measures as proximity variables creating a predictor measuring distance between left-right voter's self-placement and left-right party positions. ${ }^{26}$ For the other individual-level variables, party-specific relationships are not directly available. They can be empirically determined by estimating - separately for each stack (party) - the empirical bivariate relationship between independent variables and the party's Ptv, the 'affinities' (predicted values or 'y-hats'). The overall variable (across all parties) synthesizes the effect of the independent variables on a generic party. It is a linear transformation of original variables and it contains all the explanatory power of those variables. Predicted values are therefore similarities between voters and parties. They are centred on their means and saved as scores for the empirical analysis as party-respondent-specific predictors (van der Eijk and Franklin, 1996; van der Eijk et al., 2006).

\footnotetext{
25 Party size and party closeness are control variables that measure the importance of political supply. The first is an indirect measure of strategic considerations on voting choices according to the psychological effects of the electoral systems (Duverger, 1951; Cox, 1997). The second is a traditional measure in the European context of the party identification, whose importance in party choices has been stressed since the first seminal works in electoral research (Campbell et al., 1960).

26 Therefore, this variable measures the importance of the ideological dimension in the party choice according the proximity model (Downs, 1957).
} 
Moreover, we need a multi-level mixed-effects model because of the structure of the data consisting of multiple levels of nested groups. There are indeed, three levels: responses (individuals $\times$ parties), respondents, and countries. Responses are nested within respondents; the latter are nested within countries. Random intercepts are specified at the country and respondent level. Indeed, mixed models ${ }^{27}$ are characterized as containing both fixed and random effects. In the current analysis, we interact the sPSNS with the independent variables in the fixed portion. Therefore, we create multiplicative interaction models in order to test our conditional hypotheses. According to Hypothesis 1, we expect that as far as sPSNS becomes higher, an increase in left-right distance (or a decrease in left-right proximity) is associated with a decrease in the Ptv. Furthermore, according to Hypothesis 2 the impact of class-cleavage-related variables (i.e. working class and union membership) on Ptv should increase as sPSNS becomes higher. Finally, according to Hypothesis 3 the impact of culture-related variables (i.e. minority and religiosity) on Ptv should decrease as sPSNS becomes higher.

\section{Findings}

We proceeded to test our hypotheses by creating four models. In the first model, there are only the random intercepts for level 2 (respondent) and level 3 (country), this is the null model. Then, we included in the model (Model A) the set of independent variables presented in the previous section: socio-demographic variables, political interest, religiosity, and attitude towards the EU membership, party closeness, left-right distance, and party size. The results of estimation are presented in Table 2, which includes $b$ coefficients (with standard errors) as well as goodness-of-fit statistics. We have reported first in the table the coefficients of the predicted values for the socio-demographic variables, political interest, religiosity, and opinions on the EU membership issue; then the coefficients for party size, party closeness, and left-right distance. Finally, information about goodness of fit is reported by means of Akaike information criterion (AIC) and Bayesian information criterion (BIC) coefficients, as well as of $R^{2}$ values.

The table reports how differences in the Ptv for a party in general (the dependent variable) are shaped by differences in the independent variables. As stated previously, in a stacked data set the dependent variable is no longer the Ptv for a specific party, but the Ptv for a generic party. Moreover, $b$ coefficients for predicted value measures are like factor scores, but tuned to provide the best available linear prediction of the dependent variable. In other words, the $b$ coefficient for a specific predictor (e.g. working class) does not express the effect of any particular indicator of such predictor, but rather the importance of such a predictor in general.

\footnotetext{
27 Comprehensive treatments of mixed models are provided by, among others, Searle et al. (1992); Demidenko (2004); Rabe-Hesketh and Skrondal (2008); McCulloch et al. (2008).
} 
Table 2. Estimated effects on Ptv for a party for some predictors, along with sPSNS and interactions with sPSNS

\begin{tabular}{|c|c|c|c|c|c|c|c|c|}
\hline & \multicolumn{2}{|c|}{ Null model } & \multicolumn{2}{|c|}{ Model A } & \multicolumn{2}{|c|}{ Model B } & \multicolumn{2}{|c|}{ Model C } \\
\hline & $b$ & SE & $b$ & SE & $b$ & SE & $b$ & SE \\
\hline \multicolumn{9}{|l|}{ Fixed effects } \\
\hline Age (year of birth) & & & 0.445 & $0.027 * * *$ & 0.449 & $0.027 * * *$ & 0.446 & $0.027 * *$ \\
\hline Gender (female) & & & 0.803 & $0.046 * *$ & 0.802 & $0.046 * *$ & 0.799 & $0.046 * *$ \\
\hline Married & & & 0.595 & $0.058 * * *$ & 0.596 & $0.058 * * *$ & 0.595 & $0.058 * * *$ \\
\hline Education & & & 0.404 & $0.028 * * *$ & 0.403 & $0.028 * * *$ & 0.406 & $0.028 * * *$ \\
\hline Church attendance & & & 0.431 & $0.021 * *$ & 0.426 & $0.021 * * *$ & 0.430 & $0.021 * * *$ \\
\hline Unemployed & & & 0.460 & $0.059 * *$ & 0.461 & $0.059 * *$ & 0.461 & $0.059 * *$ \\
\hline Minority & & & 0.662 & $0.021 * *$ & 1.163 & $0.302 * * *$ & 1.173 & $0.302 * * *$ \\
\hline Family income & & & 0.309 & $0.028 * * *$ & 0.308 & $0.028 * * *$ & 0.306 & $0.028 * *$ \\
\hline Working class & & & 0.475 & $0.023 * *$ & 1.333 & $0.319 * * *$ & 1.319 & $0.319 * * *$ \\
\hline Union membership & & & 0.550 & $0.027 * *$ & 1.501 & $0.309 * * *$ & 1.492 & $0.309 * *$ \\
\hline Political interest & & & 0.685 & $0.042 * * *$ & 0.682 & $0.042 * * *$ & 0.682 & $0.042 * * *$ \\
\hline Religiosity & & & 0.339 & $0.021 * * *$ & 0.335 & $0.021 * * *$ & 1.113 & $0.215 * * *$ \\
\hline EU membership good & & & 0.594 & $0.018 * * *$ & 0.593 & $0.018 * * *$ & 0.593 & $0.018 * *$ \\
\hline Party size & & & 6.851 & $0.089 * * *$ & 6.835 & $0.089 * * *$ & 6.835 & $0.089 * * *$ \\
\hline Party closeness (dummy) & & & 3.006 & $0.065 * *$ & 3.001 & $0.065 * *$ & 3.001 & $0.065 * *$ \\
\hline Left-right distance & & & -4.996 & $0.037 * * *$ & 2.073 & $0.352 * * *$ & -1.982 & $0.353 * *$ \\
\hline sPSNS & & & & & 0.278 & 1.749 & 0.311 & 1.749 \\
\hline sPSNS $\times$ left-right distance & & & & & 3.513 & $0.421 * * *$ & -3.625 & $0.422 * * *$ \\
\hline sPSNS $\times$ working class & & & & & -1.015 & $0.375 * *$ & -1.001 & $0.375 *$ \\
\hline sPSNS $\times$ union membership & & & & & -1.135 & $0.366 * *$ & -1.124 & $0.366^{* *}$ \\
\hline sPSNS $\times$ minority & & & & & -0.621 & 0.378 & -0.635 & 0.378 \\
\hline $\mathrm{sPSNS} \times$ religiosity & & & & & & & -0.913 & $0.251 * *$ \\
\hline Constant & 3.315 & $0.120 * * *$ & 3.875 & $0.153 * * *$ & 3.648 & $1.457^{*}$ & 3.621 & $1.458 *$ \\
\hline \multicolumn{9}{|l|}{ Random effects } \\
\hline Std. dev. of respondent intercepts & 0.549 & & 0.976 & & 0.974 & & 0.975 & \\
\hline Std. dev. of country intercepts & 0.574 & & 0.727 & & 0.725 & & 0.725 & \\
\hline
\end{tabular}


Table 2. (Continued)

\begin{tabular}{|c|c|c|c|c|c|c|c|c|}
\hline & \multicolumn{2}{|c|}{ Null model } & \multicolumn{2}{|c|}{ Model A } & \multicolumn{2}{|c|}{ Model B } & \multicolumn{2}{|c|}{ Model C } \\
\hline & $b$ & SE & $b$ & SE & $b$ & SE & $b$ & SE \\
\hline \multicolumn{9}{|l|}{ Observations } \\
\hline Level 1 (response) & 120,200 & & 100,630 & & 100,630 & & 100,630 & \\
\hline Level 2 (individual) & 21,866 & & 18,919 & & 18,919 & & 18,919 & \\
\hline Level 3 (country) & 23 & & 23 & & 23 & & 23 & \\
\hline$R^{2}$ & 0.088 & & 0.431 & & 0.431 & & 0.431 & \\
\hline Residual $R^{2}$ of context variance (BLUPs) & 0.088 & & 0.130 & & 0.129 & & 0.129 & \\
\hline AIC & $638,902.061$ & & $499,621.616$ & & $499,546.855$ & & $499,535.640$ & \\
\hline $\mathrm{BIC}$ & $638,940.849$ & & $499,812.000$ & & $499,784.835$ & & $499,783.139$ & \\
\hline
\end{tabular}

Ptv = propensity to vote; sPSNS = standardized Party System Nationalization Score; EU = European Union, BLUP = best linear unbiased prediction; AIC = Akaike information criterion; BIC = Bayesian information criterion.

Variables in italics are predicted values.

Significant at $* P<0.05, * * P<0.01, * * * P<0.001$ levels. 
Therefore, $b$ coefficients for predicted values are always positive and (with regard to multi-collinearity) behave like $\beta$ coefficients. ${ }^{28}$

As we can see, the overall predictive power of Model A is good, explaining the $43 \%$ of variance. Looking at the $b$ coefficients of the predictors, we can observe that party size, party closeness, and left-right distance have the greatest influence on party support, followed by gender and political interest. However, we are not interested in the influence of each independent variable on the individual voting behaviour. Therefore, in order to test our conditional hypotheses, we included in the model the sPSNS and interacted it with the independent variables (in particular those concerned with our hypotheses), keeping all the significant interaction terms. Because sPSNS is an explicit variable in this table, the model has a cross-nested hierarchical structure, ${ }^{29}$ with an individual level falling between the country and the response level. In Model B, we present interactions between sPSNS and left-right distance, working class, union membership, and minority. The first interaction is needed in order to test Hypothesis 1, whereas the interactions between sPSNS and the two class-cleavage-related variables (working class and union membership) are needed to test Hypothesis 2. Finally, we interact sPSNS and the 'minority' variable in order to test Hypothesis 3. We have followed the strategy of analysis suggested by Brambor et al. (2006) with regard to the statistical significance of interactions, by plotting the marginal effect of $X$ on $Y$ (with a confidence interval around that marginal effect) at different values of the intervening variable $Z$ (sPSNS), in order to assess whether that marginal effect is statistically and substantively significant. The statistical significance of the coefficient of a multiplicative interaction term is considered as neither necessary nor sufficient for determining whether $X$ has an important or statistically distinguishable relationship with $Y$.

\footnotetext{
${ }^{28}$ Because predicted values are tuned to the dependent variable, in the absence of collinearity with other independent variables, their effect would be 1 . In order to control for predicted values, in spite of being centred, they are heavily correlated with one another. We have looked at the bivariate Pearson's correlations between the generated predicted values. The result is that predicted values are not picking up on the same covariance component. In addition, by regressing predicted values and party-specific predictors on the Ptv, we have calculated the variance inflation factor that is smaller than 5, meaning that there is no multicollinearity (O’Brien, 2007).

${ }^{29}$ Usually, a cross-level interaction comes together with a model specification where the slope of the lower-level variable is left free to vary across higher-level units (the so-called random effects). However, in this analysis we have several cross-level interactions at the same time. Including random slopes for all these effects raises serious computational issues and the models do not converge at all. For this reason, we have decided not to include random slopes in our models. In order to increase the robustness of our results, we have run five separate models, each one with a single cross-level interaction $(\mathrm{sPSNS} \times$ left-right distance, sPSNS $\times$ working class, sPSNS $\times$ union membership, $s P S N S \times$ minority, $s P S N S \times$ religiosity), and each one with the effect of the Level 1 variable that is interacted with sPSNS set as random. The marginal effect plots show that the results are substantially unchanged, even if the slopes of the marginal effect plots are more flat than those reported here because of the non-significance of the interaction terms. Nevertheless, the marginal effects still are all significant, confirming the reported results of the random intercept models. Furthermore, we noticed that the main effect of left-right distance is not significant when sPSNS is equal to 0: this point strengthens our argument, showing clearly how the left-right ideological dimension is an important predictor of party choice in nationalized contexts, whereas in (unrealistic) totally de-nationalized contexts it does not matter.
} 
The overall predictive power of Model B is the same as the one of Model A, but $\mathrm{AIC}$ and BIC coefficients slightly decrease. If we look at the interaction terms through the marginal effects plots, they are all statistically significant; however, the marginal effect plot for 'minority' shows the lower bound of its $95 \%$ confidence interval close to the zero line (the farthest that the lower boundary gets from the zero line is some decimal points more than 0.6). Moreover, the slope of the positive marginal effect of minority on Ptv across the observed values of sPSNS is not great and the coefficient of the interaction term, sPSNS $\times$ minority, is not significant. In Model C, we interacted sPSNS with another culture-related variable: religiosity. The overall predictive power of the explicative model is always good, explaining the $43 \%$ of variance. AIC and BIC coefficients decrease with respect to Model B, so Model C fits better than Model B.

If we look at the interactions included in the model, we achieve important results. First, sPSNS is an important intervening variable when it interacts with left-right distance. The introduction of this interaction changes the left-right distance constitutive term in the equation, which drops by almost a half, from -4.996 in Model A to -1.982 in Model C. The bulk of the work in terms of effects of left-right distance is being done by its interaction with sPSNS. As the interpretation of interaction terms is not straightforward, Figure 3 plots the marginal effect of left-right distance on Ptv across the observed values of sPSNS. The marginal effect of left-right distance is negative and significant across the observed range of sPSNS, and the interaction term is negative and significant. Moreover, the lower bound of the $95 \%$ confidence interval of the marginal effect plot for left-right distance is far from the zero line and the slope of the marginal effect of left-right distance is much more than the slope of the other variables that have been interacted with sPSNS. Therefore, there is strong empirical evidence that left-right distance and sPSNS interact in influencing Ptv. This interaction is statistically and substantively significant - more than the others in our model - and it provides empirical

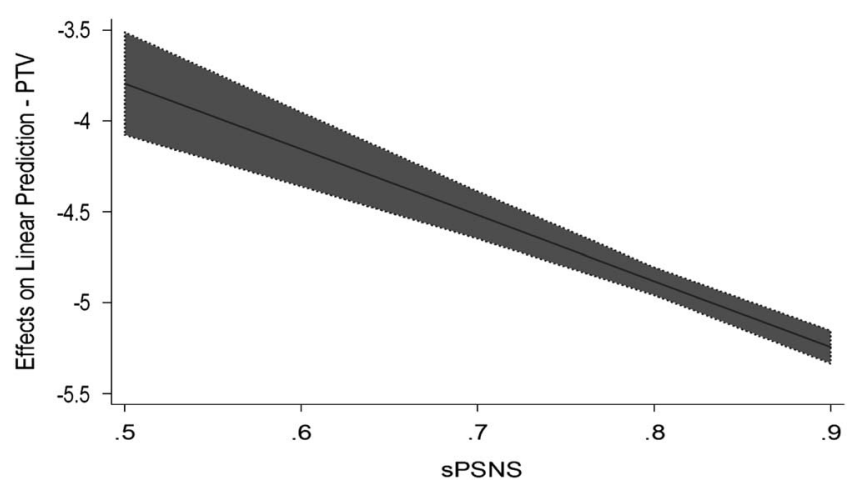

Figure 3 The marginal effect of left-right distance on Ptv. sPSNS = standardized Party System Nationalization Score; Ptv $=$ propensity to vote . 
confirmation of our first hypothesis (Hypothesis 1); as far as sPSNS becomes higher, an increase in left-right distance (or a decrease in left-right proximity) is associated with a decrease in the Ptv. These results are consistent with the literature; the pattern of party competition has been structured alongside an overwhelming left-right dimension after the democratization and nationalization of politics, weakening all the other traditional lines of political conflict. In nationalized contexts, the political space is much more one dimensional, based on the left-right distinction, as suggested by Downs (1957).

The interactions between sPSNS and the class-cleavage-related variables are significant, too. The marginal effect of working class is positive and significant across the observed range of sPSNS (Figure 4), and the interaction term is negative and significant. The same applies for union membership (Figure 5). However, the slope of the marginal effect of working class is less than the slope of union membership; substantively, this means that sPSNS interact in particular with the organizational tie of the working class in influencing the Ptv. Although the class-cleavage-related variables interact significantly with sPSNS, the conditional theory underlying Hypothesis 2 has been reversed by our empirical test: the impact of class-cleavage-related variables on Ptv decreases as sPSNS becomes higher, rather than increasing. It means that class-cleavage-related variables are no longer a strong homogenizing factor; the impact of such variables on party support is stronger in less-nationalized contexts. In other words, it seems that, nowadays, the class cleavage is rooted in heterogeneous territorial configurations.

Finally, in Model C sPSNS has been interacted with minority and (individual) religiosity. As previously seen, the slope of the marginal effect of minority on Ptv across the observed values of sPSNS is much less than the slope of the marginal effect of the other variables interacted with sPSNS and the coefficient of the interaction term, sPSNS $\times$ minority, is not significant (Figure 6). The interaction between

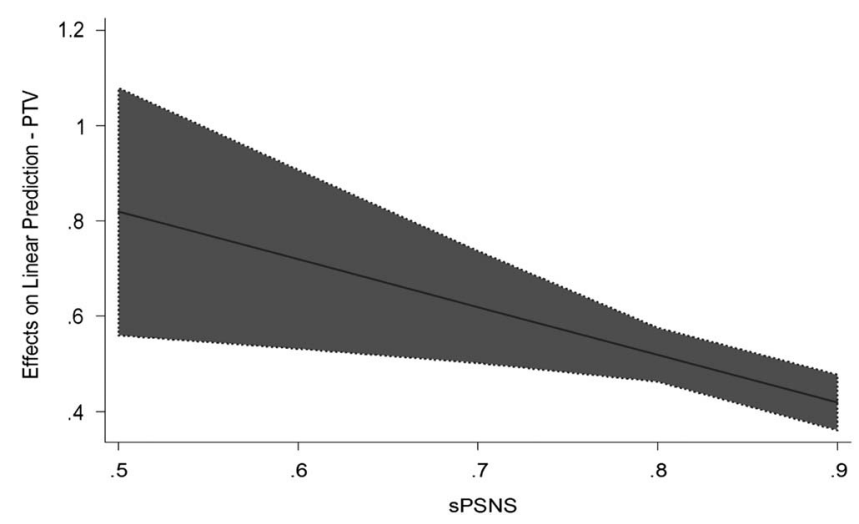

Figure 4 The marginal effect of working class on Ptv. sPSNS = standardized Party System Nationalization Score; Ptv = propensity to vote. 


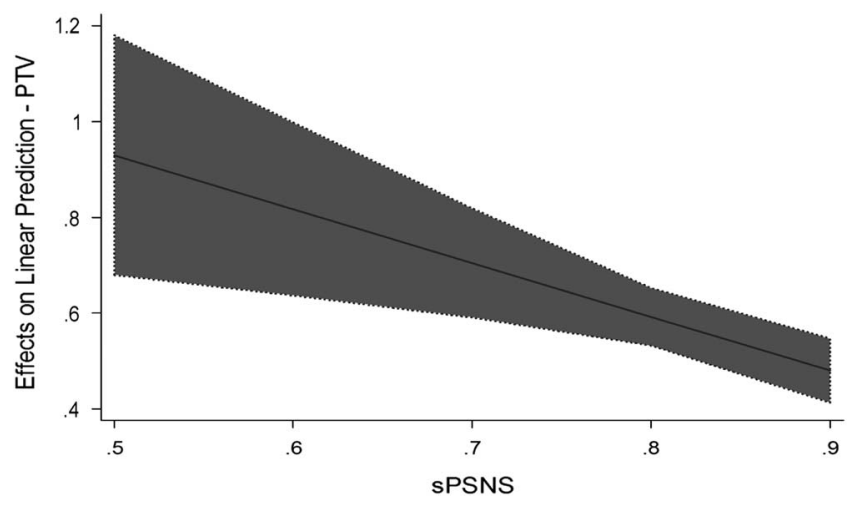

Figure 5 The marginal effect of union membership on Ptv. sPSNS = standardized Party System Nationalization Score; Ptv = propensity to vote.

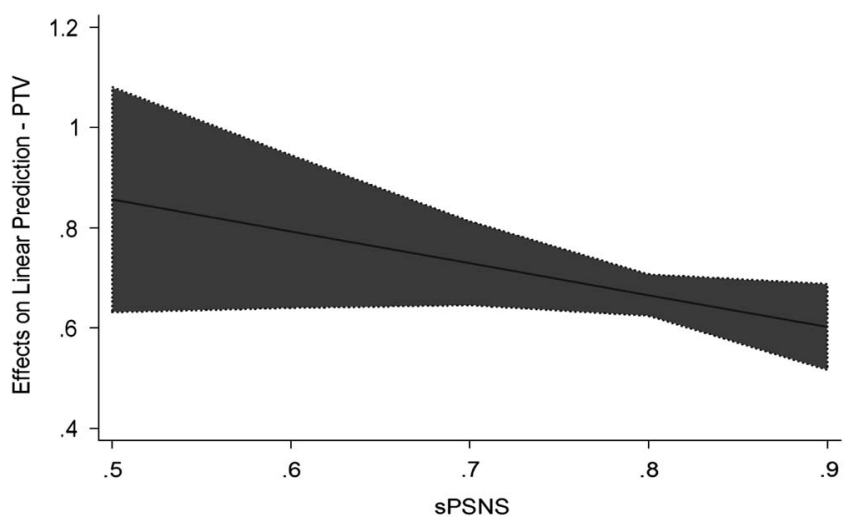

Figure 6 The marginal effect of minority on Ptv. sPSNS = standardized Party System Nationalization Score; Ptv $=$ propensity to vote.

sPSNS and religiosity is much more significant, from a statistical and substantial standpoint (Figure 7). In general, however, the underlying conditional theory of Hypothesis 3 has been confirmed by our empirical test; the impact of culture-related variables on Ptv decreases as sPSNS becomes higher.

\section{Conclusion and discussion}

The present article has tried to assess if and how PSN affects individual voting behaviour. Moving from the theoretical framework concerning the historical process of PSN in Europe, we have analysed whether PSN could act as a context dimension interacting with individual determinants of the vote choice function. 


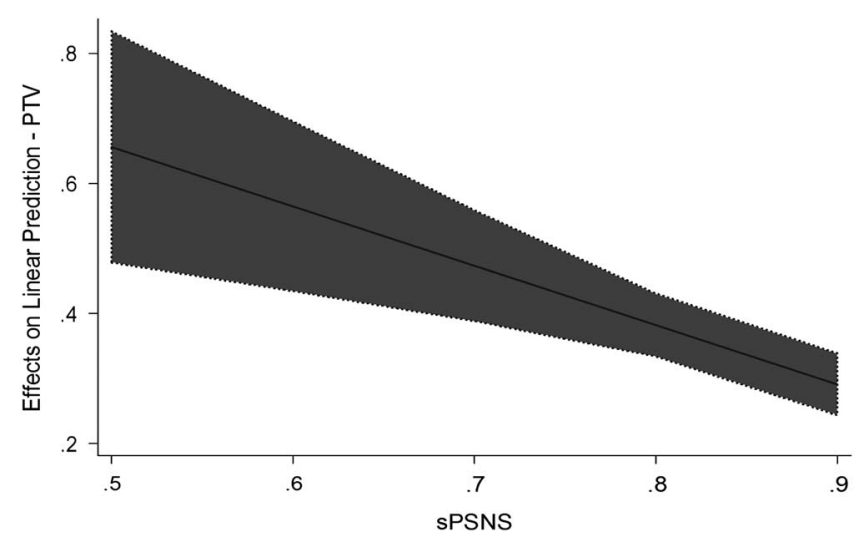

Figure 7 The marginal effect of religiosity on Ptv. sPSNS = standardized Party System Nationalization Score; Ptv = propensity to vote.

Furthermore, we have been interested to discover which determinants of vote choice PSN has a greater impact on.

The novelty of this analysis relies on the new perspective we have used to deal with the issue of PSN. Instead of considering PSN as an explanandum, we have treated it as a contextual factor, which can in turn influence individual variables and contribute to explaining the vote choice.

We have tested our hypotheses using a multi-level analysis design with a stacked data matrix. Specifically, we have tested the interaction of some individual and party-level characteristics with sPSNS in order to assess their relative impact on Ptv which, in turn, represents our dependent variable. We were expecting a stronger impact of variables such as left-right distance, as well as those related to the class cleavage on Ptv in highly nationalized contexts. Conversely, the impact of culture-related variables on Ptv should be greater in territorially heterogeneous contexts.

The findings are interesting, and to a certain extent, surprising. Although the results about the moderating effects of PSN on left-right distance and on culture-related variables prove to be consistent with the expectations, the classcleavage-related variables show a greater impact on individual voting behaviour in less-nationalized countries.

This reverses the long-time established literature emphasizing the homogenizing effect of the class cleavage. Why does this unexpected and counter-intuitive result occur? Further research will be necessary to properly answer this question. Nonetheless, we can suggest a possible explanation. The class cleavage has been one of the most important determinants of voting behaviour since the development of mass democracies. As it has been emphasized by several empirical studies (Franklin et al., 1992; Dalton, 2002), the class cleavage has experienced an irreversible decline in recent decades. Not only has the number of people identifying with a specific class 
dramatically dropped, but the salience of this variable as an explanatory factor of voting behaviour has also noticeably diminished. As a consequence, we may hypothesize that in the wake of this weakening, the class cleavage in Europe has undergone a progressive territorialization, thus losing to some extent, its original nature as a nationwide and functional cleavage. In this regard, it seems that the class cleavage, just as the cultural factors (ethnicity, language, and religion), is more and more linked to certain territorial specificities instead of being the 'homogenizing factor' highlighted by Caramani (2004: 196). Furthermore, it follows that, nowadays, the class cleavage no longer overlaps with the left-right dimension, which, on the contrary, is still one of the most important determinants of the vote choice. Moreover, the impact of the left-right dimension increases in nationalized contexts.

In conclusion, in nationalized party systems, political conflict occurs in a single left-right dimension, which is very important to explain party choice - more so than in party systems with lower levels of nationalization. Conversely, cultural and class identities are rooted in heterogeneous territorial configurations, and this territorial heterogeneity weakens the importance of political distinction based on the left-right dimension in explaining voting behaviour.

\section{Acknowledgement}

The authors thank Alessandro Chiaramonte and Lorenzo De Sio for useful feedback on earlier drafts of this article.

\section{Financial Support}

The research received no grants from public, commercial, or non-profit funding agency.

\section{Data}

The replication data set is available at http://thedata.harvard.edu/dvn/dv/ipsr-risp.

\section{References}

Agnew, J. (1987), Place and Politics. The Geographical Mediations of State and Society, London: Allen and Unwin.

Andreadis, I. (2011), Indexes of party nationalization. Paper presented at The True European Voter Conference, September 23, University of Wien, Austria.

Bartolini, S. (2000), The Political Mobilization of the European Left, 1860-1980: The Class Cleavage, Cambridge, UK: Cambridge University Press.

Bartolini, S. and P. Mair (1990), Identity, Competition, and Electoral Availability: The Stabilisation of European Electorates 1885-1985, Cambridge, UK: Cambridge University Press.

Berelson, B., P.F. Lazarsfeld, and W.N. McPhee (1954), Voting. A Study of Opinion Formation in a Presidential Campaign, Chicago, IL: University of Chicago Press.

Bochsler, D. (2010a), 'Measuring party nationalisation: a new Gini-based indicator that corrects for the number of units', Electoral Studies 29: 155-168.

— (2010b), 'The nationalization of post-communist party systems', Europe-Asia Studies 62: 807-827. 
Brambor, T., W.R. Clark, and M. Golder (2006), 'Understanding interaction models: improving empirical analyses', Political Analysis 14(1): 63-82.

Campbell, A., P.E. Converse, W.E. Miller, and D. Stokes (1960), The American Voter, New York, NY: Wiley.

Caramani, D. (2004), The Nationalization of Politics: The Formation of National Electorates and Party Systems in Western Europe, Cambridge, UK: Cambridge University Press.

- (2005), 'The formation of national party systems in Europe: a comparative-historical analysis', Scandinavian Political Studies 28(4): 295-322.

Castañeda-Angarita, N. (2013), 'Party system nationalization, presidential coalitions, and government spending', Electoral Studies 30(1): 1-12.

Chhibber, P. and K. Kollman (2004), The formation of National party systems: Federalism and party competition in Canada, Great Britain, India, and the United States, Princeton, NJ: Princeton University Press. (2004), The Formation of National Party Systems: Federalism and Party Competition in Canada, Great Britain, India, and the United States, Princeton, NJ: Princeton University Press.

Chiaramonte, A. (2007), 'Il nuovo sistema partitico italiano tra bipolarismo e frammentazione', in R. D'Alimonte and A. Chiaramonte (eds), Proporzionale ma non solo. Le elezioni politiche del 2006, Bologna: Il Mulino, 369-406.

Converse, P.E. (1975), 'Public opinion and voting behaviour', in F.I. Greenstein and N.W. Polsby (eds), Handbook of Political Science 4, Reading, UK: Addison-Wesley, 75-169.

Cox, G.W. (1997), Making Votes Count. Strategic Consideration in the World's Electoral Systems, Cambridge, UK: Cambridge University Press.

- (1999), 'Electoral rules and electoral coordination', Annual Review of Political Science 2: $145-161$.

Dalton, R.J. (2002), 'Political cleavage, issues, and electoral change', in L. Le Duc, R.G. Niemi and P. Norris (eds), Comparing Democracy 2: New Challenges in the Study of Elections and Voting, London: SAGE Publications, 189-209.

Dalton, R.J., and C.J. Anderson (eds). (2011), Citizens, Context, and Choice: How Context Shapes Citizens' Electoral Choices, Oxford, UK: Oxford University Press.

Dalton, R.J., S.C. Flanagan, and P.A. Beck (1984), Electoral Change in Advanced Industrial Democracies, Princeton, NJ: Princeton University Press.

Demidenko, E. (2004), Mixed Models: Theory and Applications, Hoboken, NJ: Wiley.

De Sio, L. and M.N. Franklin (2012), 'Strategic incentives, issue proximity and party system support in Europe', West European Politics 35(6): 1363-1385.

De Winter, L. and P. Dumont (1999), 'Belgium: party system(s) on the eve of disintegration?', in D. Broughton and M. Donovan (eds), Changing Party Systems in Western Europe, London and New York, NY: Pinter, 183-206.

Downs, A. (1957), An Economic Theory of Democracy, New York, NY: Harper and Row.

Duverger, M. (1951), Political Parties: Their Organization and Activity in the Modern State, New York, NY: Wiley.

Elster, J., C. Offe, and U.K. Preuss (1998), Institutional Design in Post-Communist Societies, Cambridge, UK: Cambridge University Press.

Ersson, S., K. Janda, and J.-E. Lane (1985), 'Ecology of party strength in Western Europe. A regional analysis', Comparative Political Studies 18: 170-205.

Evans, G. and A. Need (2002), 'Explaining ethnic polarization over attitudes towards minority rights in Eastern Europe: a multilevel analysis', Social Science Research 31(4): 653-680.

Franklin, M., T. Mackie, and H. Valen (eds). (1992), Electoral Change. Responses to Evolving Social and Attitudinal Structures in Western Countries, Cambridge: Cambridge University Press.

Gallagher, M. (1998), 'Il comportamento elettorale in Irlanda dal 1969 al 1997', Quaderni dell'Osservatorio Elettorale 40: 71-98.

Grilli di Cortona, P. (2007), 'Polonia: un sistema partitico in cerca di istituzionalizzazione', in P.G. di Cortona and G. Pasquino (eds), Partiti e Sistemi di Partito Nelle Democrazie Contemporanee, Bologna: Il Mulino, 213-242.

Hicken, A., K. Kollman, and J. Simmons (2008), 'Party system nationalization and the provision of public health services’. Working Paper, University of Michigan, Ann Arbor, MI. 
Hirschman, A. (1970), Exit, Voice and Loyalty: Responses to Decline in Firms, Organizations and States, Cambridge, MA: Harvard University Press.

Huckfeldt, R. and J. Sprague (1993), 'Citizens, contexts, and politics', in A.W. Finifter (ed.), Political Science: The State of the Discipline II, Washington, DC: American Political Science Association, 281-303.

Jones, M.P. and S. Mainwaring (2003), 'The nationalization of parties and party systems: an empirical measure and an application to the Americas', Party Politics 9: 139-166.

Klingemann, H.-D. (2009), 'The impact of political institutions: a contribution of the 'Comparative Study of Electoral Systems' (CSES) to micro-macro theories of political attitude formation and voting behavior', in H.-D. Klingemann (ed.), The Comparative Study of Electoral Systems, Oxford: Oxford University Press, 3-27.

Kuechler, M. (1991), 'Issues and voting in the European elections 1989', European Journal of Political Research 19: 81-103.

Laakso, M. and R. Taagepera (1979), “Effective” number of parties: A measure with application to West Europe', Comparative Political Studies 12: 3-27.

Lago, I. and S. Lago (2010), 'Decentralization and nationalization of party systems'. International Studies Program Working Paper No. 10/06, Georgia State University, Atlanta, GA.

Lane, J.E. and S. Ersson (1990), 'Comparative politics: From political sociology to comparative public policy', in A. Leftwitch (ed.), New developments in political science: An International Review of Past Achievements and Future Prospects, London: Elgar, 61-81.

Lazarsfeld, P., B. Berelson, and H. Gaudet (1944), The People's Choice. How the Voter Makes Up his Mind in a Presidential Campaign, New York, NY: Columbia University Press.

Lipset, S.M. and S. Rokkan (1967), 'Cleavage structures, party systems and voter alignments: an introduction', in S.M. Lipset and S. Rokkan (eds), Party Systems and Voter Alignments: Cross-National Perspectives, New York, NY: The Free Press, 1-64.

Marsh, M. (2002), 'Electoral context', Electoral Studies 21: 207-217.

McCulloch, C.E., S.R. Searle, and J.M. Neuhaus (2008), Generalized, Linear, and Mixed Models, 2nd edn., Hoboken, NJ: Wiley.

Morgenstern, S., J. Polga-Hecimovich, and P.M. Siavelis (2014), 'Seven imperatives for improving the measurement of party nationalization with evidence from Chile', Electoral Studies 33(1): 186-199.

Morgenstern, S., S.M. Swindle, and A. Castagnola (2009), 'Party nationalization and institutions', Journal of Politics 71: 1322-1341.

O’Brien, R.M. (2007), 'A caution regarding rules of thumb for variance inflation factors', Quality \& Quantity 41(5): 673-690.

Rabe-Hesketh, S. and A. Skrondal (2008), Multilevel and Longitudinal Modeling Using Stata, 2nd edn., College Station, TX: Stata Press.

Reif, K. and H. Schmitt (1980), 'Nine second order national elections. A conceptual framework for the analysis of European election results', European Journal of Political Research 8(1): 3-44.

Rokkan, S. (1970), Citizens, Elections, Parties, Oslo, Norway: Universitetsforlaget.

Rokkan, S. and D.W. Urwin (eds). (1982), The Politics of Territorial Identity. Studies in European Regionalism, London, UK: Sage.

Rose, R. and D.W. Urwin (1975), Regional Differentiation and Political Unity in Western Nations, Beverly Hills, CA: Sage.

Sartori, G. (1976), Parties and Party Systems: A Framework of Analysis, New York, NY: Cambridge University Press.

Schattschneider, E.E. (1960), The Semi-Sovereign People: A Realist's View of Democracy in America, New York, NY: Holt, Rinehart, and Winston.

Searle, S.R., G. Casella, and C.E. McCulloch (1992), Variance Components, New York, NY: Wiley.

Siegfried, A. (1913), Tableu Politique de la France de l'Ouest Sous la Troisième République, Paris: A. Colin.

Sikk, A. (2005), 'How unstable? Volatility and the genuinely new parties in Eastern Europe', European Journal of Political Research 44: 391-412. 
Sikk, A. and D. Bochsler (2008), 'Impact of ethnic heterogeneity on party nationalization in the Baltic states: the nationalisation of party systems in Central and Eastern Europe'. Paper presented at the ECPR Joint Sessions of Workshop, April 11-16, University of Rennes.

Smith, E.R.A.N. (1989), The Unchanging American Voter, Berkeley and Los Angeles, CA: University of California Press.

Stokes, D.E. (1965), 'A variance components model of political effects', in J.M. Claunch (ed.), Mathematical Applications in Political Science, Dallas, TX: Southern Methodist University Press, 61-85.

— (1967), 'Parties and the nationalization of electoral forces', in W.N. Chambers and W.D. Burnham (eds), The American Party Systems: Stages of Political Development, New York, NY: Oxford University Press, 182-202.

Tavits, M. (2005), 'The development of stable party support: electoral dynamics in postcommunist Europe', American Journal of Political Science 49(2): 283-298.

Tilly, C. (ed.) (1975), The Formation of National States in Western Europe, Princeton, NJ: Princeton University Press.

Thomassen, J.J.A (ed.) (2005), The European Voter. A Comparative Study of Modern Democracies, Oxford: Oxford University Press.

Torsvik, P. (1981), Mobilization, Center-Periphery Structures and Nation Building. A Volume in Commemoration of Stein Rokkan, Oslo: Universitetsforlaget.

Urwin, D.W. (1982), 'Territorial structures and political development in the United Kingdom', in S. Rokkan and D.W. Urwin (eds), The Politics of Territorial Identity. Studies in European Regionalism, London, UK: Sage, 19-74.

van der Brug, W., M.N. Franklin, and G. Toka (2008), 'One electorate or many? Differences in party preference formation between new and established European democracies', Electoral Studies 27(4): 589-600.

van der Eijk, C. and M.N. Franklin (1996), Choosing Europe? The European Electorate and National Politics in the Face of the Union, Ann Arbor, MI: The University of Michigan Press.

van der Eijk, C. and M.N. Franklin (2009), Elections and Voters, Hampshire, UK: Palgrave Macmillan.

van der Eijk, C., W. van der Brug, M. Kroh, and M.N. Franklin (2006), 'Rethinking the dependent variable in voting behaviour: on the measurement and analysis of electoral utilities', Electoral Studies 25(3): 424-447.

van Egmond, M., W. van der Brug, S. Hobold, M.N. Franklin, and E.V. Sapir (2011), European Parliament Election Study 2009, Voter Study, Köln, Germany: GESIS Datenarchiv. 